\title{
Domestic biomass fuel combustion and chronic bronchitis in two rural Bolivian villages
}

\author{
R Albalak, A R Frisancho, G J Keeler
}

\begin{abstract}
Background-Chronic bronchitis is an important public health problem worldwide. A study was undertaken to examine the association between exposure to air pollution from domestic biomass fuel combustion and chronic bronchitis in two rural Bolivian highland villages: a village in which cooking is done exclusively indoors and a village in which cooking is done primarily outdoors. Apart from this difference, the villages were virtually identical in terms of socioeconomic status, climate, altitude, access to health care, and other potential confounders.
\end{abstract}

Methods-Pollution exposure was assessed by combining information on concentrations of particulate matter of $<10 \mu \mathrm{m}$ diameter $\left(\mathbf{P M}_{10}\right)$ in 12 randomly selected households in each village in all potential microenvironments of exposure with time allocation information. The prevalence of chronic bronchitis was assessed using the British Medical Research Council's questionnaire on individuals $>20$ years of age in both villages $(n=241)$. Results-Daily pollution exposure was significantly higher in the indoor cooking village (range for adults: 9840-15 $120 \mu \mathrm{g}-\mathrm{h} /$ $\mathrm{m}^{3}$ ) than in the outdoor cooking village (range for adults: $5520-6240 \mu \mathrm{g}-\mathrm{h} / \mathrm{m}^{3}$ ) for both seasons and for men and women. The overall prevalence of chronic bronchitis was $22 \%$ and $13 \%$ for the indoor and outdoor cooking villages, respectively. Logistic regression analysis, which excluded the few smokers present in the population, showed a $60 \%$ reduced risk of chronic bronchitis in the outdoor cooking village compared with the indoor cooking village (OR $0.4 ; 95 \%$ CI 0.2 to $0.8 ; p=0.0102$ ) after adjusting for age and sex. Individuals aged $>40$ years were 4.3 times more likely to have chronic bronchitis than the younger age group $(\mathrm{OR}=4.3 ; 95 \%$ CI 2.0 to $9.3 ; \mathrm{p}=$ $0.0002)$. There was no significant difference in the prevalence of chronic bronchitis in men and women.

Conclusions-The results of this study suggest an association between chronic bronchitis and exposure to domestic biomass fuel combustion, but further large scale studies from other areas of the developing world are needed to confirm the association. Results from this and other studies will assist the development of culturally acceptable and feasible alternatives to the high exposure cooking stoves currently being used by most people worldwide.

(Thorax 1999;54:1004-1008)

Keywords: chronic bronchitis; air pollution; cooking fuel; Bolivia

Chronic bronchitis is an important public health problem worldwide, despite the fact that it is potentially a preventable disease. ${ }^{1}$ In developed countries the prevalence of chronic bronchitis ranges from $3 \%$ to $17 \%^{2}$ while in developing countries (with a few exceptions ${ }^{3}{ }^{4}$ ) the rates are higher, ranging from $13 \%$ to $27 \% .^{2}$ Population studies from developed countries have established smoking as one of the primary risk factors for the development of chronic bronchitis. ${ }^{5}$ This explains the often much higher prevalence rates in men than in women since men are more likely to smoke. ${ }^{6}$ In rural areas of developing countries, on the other hand, where smoking is uncommon among women, studies have shown similar rates of chronic bronchitis between men and women. ${ }^{7-9}$ This may be explained by another potential risk factor for the development of chronic bronchitis-namely, smoke from domestic biomass fuel combustion.

It has been estimated that roughly half the world's population cooks daily with unprocessed biomass fuels. ${ }^{10}$ Most of these people live in rural areas of developing countries where about $80 \%$ of households rely on biomass fuels as their major or only source of domestic energy for cooking and sometimes space heating. ${ }^{11}$ The widespread use of biomass fuels indoors leads to levels of pollution that are among the highest ever measured. ${ }^{10}$ Since people in rural areas of developing countries spend many hours a day cooking, exposure to these high levels is considerable, especially among women and children. In its 1993 annual report the World Bank estimated that indoor air pollution is responsible for almost $50 \%$ of the burden of total disease resulting from poor household environments in geographically developing countries. ${ }^{12}$ This was due overwhelmingly to an assumed relationship with acute respiratory infections in children and chronic obstructive lung disease in adults. Despite the high exposure to indoor air pollution on a global basis and its assumed association with respiratory disease, few studies have examined it as a risk factor in the development of chronic bronchitis. We have therefore examined the relationship between exposure to domestic biomass fuel combustion and chronic bronchitis based on a one year study conducted in two rural Bolivian highland villages — a village in 
which cooking is done exclusively indoors and one in which cooking is done primarily out of doors.

\section{Methods}

STUDY POPULATION

The study was conducted in Bolivia in two rural indigenous Aymara communities, Cantuyo and Taipillanga. Despite a geographical distance between the villages of approximately $150 \mathrm{~km}$, they were very similar. Both villages are located at an altitude of approximately $13000 \mathrm{ft}(4100 \mathrm{~m})$ above sea level resulting in a frigid climate with sparse vegetation. The villages are small ( 50 households in Cantuyo, 132 males and 138 females; 61 households in Taipillanga, 160 males and 159 females) and the households widely dispersed. They were virtually indistinguishable from each other in terms of socioeconomic status, economy, diet, home construction, and access to health care. They were matched on these key characteristics in order to minimise the potential for confounding.

In both villages cooking is done on a traditional cooking stove called in Aymara a keree. The fuel, almost exclusively cow dung, is placed in a hole that is carved out of the middle part of the stove below the area for the pots and pans. The only major difference between the two study villages is in the construction of the kitchens and the resulting differences in cooking habits and activity patterns. In Cantuyo cooking is done exclusively indoors in small adobe kitchens with thatched roofs and little or no ventilation. The stove is located in the corner of the kitchen. Cooking is done in the morning and in the evening before and after going out to work in the fields. The family sits in front of the cooking fires as protection from the cold highland morning and evening temperatures. This follows the typical Bolivian highland pattern. In Taipillanga, on the other hand, cooking is done almost exclusively out of doors in an area defined by a semicircular wall made of a root plant piled several feet high. The stove is placed adjacent to the "wall". Because of the cold highland temperatures, only the mother goes out to cook and returns to the living area while the food is cooking. The living area and kitchen are separate structures in both villages. The villagers explain that they began cooking in this manner approximately 60 years ago because the smoke made them sick. When asked about the change, one man said that "his mother coughed to death because of the smoke". Outdoor cooking is a rarity in the Bolivian highlands and presented a unique opportunity for comparing the respiratory health of the two villages.

\section{EXPOSURE TO AIR POLLUTION}

Daily integrated pollution exposure was measured by using information on concentrations of particulate matter with an aerodynamic diameter of $<10 \mu \mathrm{m}\left(\mathrm{PM}_{10}\right)$ in conjunction with information on time activity patterns. Details of the $\mathrm{PM}_{10}$ sampling protocol and the calculation of total human exposure are presented elsewhere. ${ }^{13}$ Briefly, $\mathrm{PM}_{10}$ concentrations were measured in the three microenvironments of exposure (kitchen, living area, and outdoors) in 12 randomly selected households in each village. The 12 households in each village were a random subset of the population that was assessed for chronic bronchitis. Households were monitored over a period of 10 months (January 1995 to October 1995) in accordance with the EPA reference method for monitoring $\mathrm{PM}_{10}$ for a total of 621 samples. A detailed time/ budget analysis of the population was carried out by questionnaire and observation. Daily integrated pollution exposure was calculated by multiplying the time spent in each microenvironment by the concentration in that microenvironment and then adding the values for each microenvironment.

\section{CHRONIC BRONCHITIS}

A preliminary census of all households in the two study villages was carried out to identify eligible subjects. All adults aged $>20$ years who agreed to participate in the study were then interviewed between March and June 1995 using the British Medical Research Council's questionnaire for the diagnosis of symptomatic chronic bronchitis. ${ }^{14}$ This questionnaire, in varying forms, has been used extensively in epidemiological studies of the prevalence of chronic bronchitis. A response rate of $90 \%$ and $95 \%$ was obtained in the indoor and outdoor cooking villages, respectively, with no obvious differences between responders and nonresponders in terms of age distribution, socioeconomic status, and other key characteristics. This is probably due to the homogeneous living conditions of the population. Non-responders were generally not at home when the household was visited and then revisited. Only two subjects, both from the indoor cooking village, refused to participate.

The MRC questionnaire was slightly modified to suit local conditions-for example, instead of "winter" and "summer" it referred to "dry season" and "wet season", and demographic information, socioeconomic status, information on housing characteristics, coca chewing habits, and smoking habits were incorporated into it. Smokers were defined as those who regularly smoked one or more cigarettes a day; past smokers were those who had smoked one or more cigarettes a day for at least a year but currently smoked less than this; and non-smokers were those who had never smoked or who had smoked less than one cigarette or equivalent a day in the past.

Using the questionnaire, individuals were diagnosed as having symptomatic chronic bronchitis based on the MRC definition of chronic bronchitis as cough and sputum production on most days for at least three consecutive months of at least two successive years. Cough and sputum production refers to morning or daytime/night time cough and sputum production, or both. A total of 241 subjects were interviewed, 102 in the indoor cooking village and 139 in the outdoor cooking village. The small sample sizes reflect the small and very dispersed nature of villages and households in the Bolivian highlands. 
Table 1 Smoking status, socioeconomic status, and characteristics of households in the two villages

\begin{tabular}{|c|c|c|}
\hline \multirow[b]{2}{*}{ Variables } & \multirow{2}{*}{$\begin{array}{l}\begin{array}{l}\text { Indoor cooking village } \\
(n=102)\end{array} \\
\text { No. }(\%)\end{array}$} & \multirow{2}{*}{$\begin{array}{l}\begin{array}{l}\text { Outdoor cooking village } \\
(n=139)\end{array} \\
\text { No. }(\%)\end{array}$} \\
\hline & & \\
\hline \multicolumn{3}{|l|}{ Smoking status in adults } \\
\hline Smokers & $1(<1)$ & $1(<1)$ \\
\hline Past smokers & $0(0)$ & $3(2)$ \\
\hline Non-smokers & $101(98)$ & $1135(97)$ \\
\hline & $(n=50)$ & $(n=61)$ \\
\hline \multicolumn{3}{|c|}{ Socioeconomic status per household } \\
\hline Electricity & $0(0)$ & $0(0)$ \\
\hline Running water & $0(0)$ & $0(0)$ \\
\hline Bicycle & $50(100)$ & $61(100)$ \\
\hline Radio & $48(96)$ & $59(97)$ \\
\hline Television & $0(0)$ & $1(1.6)$ \\
\hline Car & $0(0)$ & $0(0)$ \\
\hline \multicolumn{3}{|l|}{ Subsistence base } \\
\hline Agriculturalists & $50(100)$ & $61(100)$ \\
\hline \multicolumn{3}{|c|}{ Living area construction materials } \\
\hline Adobe with tin roof & $48(96)$ & $61(100)$ \\
\hline Adobe with thatched roof & $2(4)$ & $0(0)$ \\
\hline \multicolumn{3}{|l|}{ Religion } \\
\hline Catholic & $40(80)$ & $47(77)$ \\
\hline Evangelical & $10(20)$ & $14(23)$ \\
\hline
\end{tabular}

The living area was a separate structure from the kitchen in both villages.

The questionnaires were translated into Spanish and all were administered by the first author of this paper to ensure uniformity and consistency in the questioning of the subjects. Since most women in both villages did not speak Spanish and since most men in both villages felt more comfortable in Aymara, an Aymara translator was used when necessary. A single translator was chosen in each village and trained in the manner of questioning so as to ensure accurate translation and uniform and consistent questioning by the translator. Each interview was done twice at an interval of two weeks to ensure that the answers given were consistent. Where a reply to a question was contradictory, this was pointed out to the subject who was asked to state what he/she thought to be the correct answer.

ANALYSIS OF DATA

Descriptive statistics were calculated for smoking, socioeconomic status, housing and village characteristics, and the prevalence of chronic bronchitis. Logistic regression analysis was used to examine the relationship between exposure to pollution and chronic bronchitis. The village was used as the exposure variable (indoor cooking village/high exposure $=0$; outdoor cooking village/low exposure $=1$ ) since the analysis of pollution exposure showed significantly higher total daily exposure to particulate pollution in the indoor cooking village than in the outdoor cooking village for men and women for both seasons. Age $(20-40=0 ;>40$ $=1$ ) and sex (male $=0$; female $=1$ ) were controlled for in the analysis and smokers and past smokers were excluded. Since smoking is extremely uncommon in the rural villages, this excluded only four people. Crude odds ratios and age and sex adjusted odds ratios and 95\% confidence intervals were calculated. $\mathrm{p}$ values of $<0.05$ were considered significant. Statistical analysis was carried out using Statistical Analysis Software (SAS). Interactions were not significant and therefore were not included in the final model. Socioeconomic status was not included in the analysis because there was no variation in this variable.

\section{Results}

The results from the pollution exposure assessment are presented in detail elsewhere. ${ }^{13}$ In sum, the geometric mean (SE) kitchen concentrations were $1830(2990) \mu \mathrm{g} / \mathrm{m}^{3}$ and $430(140) \mu \mathrm{g} / \mathrm{m}^{3}$ in the indoor and outdoor cooking villages, respectively. In the indoor cooking village approximately $35 \%$ of the time was spent in the kitchen compared with only about $7 \%$ in the outdoor cooking village. Total daily integrated $\mathrm{PM}_{10}$ exposure in the indoor cooking village ranged from $9840 \mu \mathrm{g}-\mathrm{h} / \mathrm{m}^{3}$ to $13680 \mu \mathrm{g}-\mathrm{h} / \mathrm{m}^{3}$ for men and from $11280 \mu \mathrm{g}-\mathrm{h} / \mathrm{m}^{3}$ to $15120 \mu \mathrm{g}-\mathrm{h} / \mathrm{m}^{3}$ for women. Total daily integrated $\mathrm{PM}_{10}$ exposure in the outdoor cooking village ranged from $5520 \mu \mathrm{g}-\mathrm{h} / \mathrm{m}^{3}$ to $6240 \mu \mathrm{g}-\mathrm{h} / \mathrm{m}^{3}$ for men and from $5760 \mu \mathrm{g}-\mathrm{h} / \mathrm{m}^{3}$ to $6000 \mu \mathrm{g}-\mathrm{h} / \mathrm{m}^{3}$ for women. The higher than expected total daily exposure in the outdoor cooking village was due to the relatively high $\mathrm{PM}_{10}$ concentrations in the homes (mostly from dust particles rather than combustible material) and the large amount of time spent in the homes in this village. However, exposure was significantly higher in the indoor cooking village than in the outdoor cooking village for both seasons and for men and women.

Table 1 presents data on smoking status, socioeconomic status, and household and village characteristics. Very few villagers were smokers or past smokers since smoking is too expensive, given the extreme poverty in these villages. The kitchen and living areas of all households in both villages were made of adobe with a dirt floor. Neither village had electricity or running water. Households had individuals wells (without pumps) for water. Nearly everyone in both villages had a bicycle and radio and both villages were approximately $7 \mathrm{~km}$ from the nearest health post. All households were subsistence agriculturalists although most also sold cheese and other homemade products at weekly markets. They used the money to buy sugar, salt, and other essential condiments and foods.

The overall prevalence of chronic bronchitis was $22 \%$ and $13 \%$ for the indoor and outdoor cooking villages, respectively. The prevalences were consistently higher in the older age group and in the indoor cooking village, and slightly higher among men (table 2).

Table 3 presents unadjusted and adjusted odds ratios for the logistic regression analysis of

Table 2 Prevalence of chronic bronchitis by village, age, and sex*

\begin{tabular}{|c|c|c|c|c|}
\hline \multirow[b]{3}{*}{ Age (years) } & \multicolumn{4}{|c|}{ Prevalence of chronic bronchitis (\%) } \\
\hline & \multicolumn{2}{|c|}{$\begin{array}{l}\text { Indoor cooking } \\
\text { village }(n=101)\end{array}$} & \multicolumn{2}{|c|}{$\begin{array}{l}\text { Outdoor cooking } \\
\text { village }(n=136)\end{array}$} \\
\hline & $n^{\star *}$ & $\begin{array}{l}\% \text { with } \\
\text { bronchitis }\end{array}$ & $n^{\star *}$ & $\begin{array}{l}\% \text { with } \\
\text { bronchitis }\end{array}$ \\
\hline \multicolumn{5}{|l|}{ Men } \\
\hline $20-40$ & 16 & 19 & 35 & 6 \\
\hline$>40$ & 19 & 37 & 29 & 24 \\
\hline \multicolumn{5}{|l|}{ Women } \\
\hline $20-40$ & 42 & 10 & 35 & 3 \\
\hline$>40$ & 24 & 33 & 37 & 19 \\
\hline
\end{tabular}

${ }^{\star}$ Prevalence rates exclude smokers and past smokers. ${ }^{\star}$ Number of people examined. 
Table 3 Logistic regression model examining the effect of village characteristics on the prevalence of chronic bronchitis, adjusting for age and sex

\begin{tabular}{lllll}
\hline & $\begin{array}{l}\text { Unadjusted } \text { OR } \\
\text { (95\% CI) }\end{array}$ & p value & $\begin{array}{l}\text { Adjusted } \text { OR } \\
\text { (95\% CI) }\end{array}$ & p value \\
\hline Village $(0=$ indoor; $1=$ outdoor) & $0.5(0.2$ to 0.9$)$ & 0.0260 & $0.4(0.2$ to 0.8$)$ & 0.0102 \\
Age $(0=20-40 ; 1=>40)$ & $4.0(1.9$ to 8.5$)$ & 0.0002 & $4.3(2.0$ to 9.3$)$ & 0.0002 \\
Sex $(0=$ male; $1=$ female) & $0.8(0.4$ to 1.6$)$ & 0.5050 & $0.8(0.4$ to 1.6$)$ & 0.4659
\end{tabular}

the relationship between pollution exposure and chronic bronchitis. Both unadjusted and adjusted odds ratios yielded similar results. The adjusted model showed a $60 \%$ reduced risk of chronic bronchitis in the outdoor cooking village compared with the indoor cooking village (OR $0.4 ; 95 \%$ CI 0.2 to $0.8 ; p=0.0102$ ) after adjusting for age and sex. Individuals in the $>40$ age group were 4.3 times more likely to have chronic bronchitis than the younger age group (OR 4.3; 95\% CI 2.0 to 9.3; $\mathrm{p}=$ $0.0002)$. Although the prevalences were consistently slightly higher in men, the relationship was not significant and not related to age as the adjusted model showed the same results as the unadjusted model.

\section{Discussion}

Prevalence rates of chronic bronchitis in this study are comparable to prevalence rates from other studies in rural areas of developing countries. ${ }^{7-9} 15$ However, much higher ${ }^{16}$ and much lower rates ${ }^{3417}$ have also been observed. It may be that rural communities with lower rates of chronic bronchitis have switched to using fuels higher up the energy ladder-for example, LPG, kerosene-for their cooking needs.

Contrary to the trend in developed countries and urban areas of developing countries in which the prevalence is generally higher in men, in all the studies where both men and women were included the prevalence was either similar between the two $^{4-9}$ or much higher in women. ${ }^{16}$ The high prevalence rate in women in the present study and a number of other studies cannot be explained by smoking since, in this study, smokers were excluded from the analysis and, in the other studies, women were very light smokers. The increase in prevalence with age is in agreement with studies from Nepal, ${ }^{7}$ New Guinea, ${ }^{8}$ and England. ${ }^{18}$ Studies from the United States ${ }^{19}$ and Canada, ${ }^{20}$ however, have failed to show an increase with age.

Results from the logistic regression analysis suggest that, in addition to age, exposure to domestic biomass fuel combustion is a risk factor for the development of chronic bronchitis. This may explain the similar rates found in men and women. These results are in agreement with the rural Nepalese study in which Pandey found that, both with and without adjusting for age, there was an increase in the prevalence of chronic bronchitis as indoor air pollution exposure increased among smokers, non-smokers, and past smokers. ${ }^{21}$ In a hospital based case-control study in Bogota, Columbia, Dennis and colleagues found that exposure to wood smoke is associated with obstructive airway disease in women and that the exposure may help to explain approximately $50 \%$ of all cases of obstructive airway disease..$^{22} \mathrm{~A}$ study in women living in low income suburbs of Maputo, Mozambique showed that wood users had more cough symptoms than other groups such as those using LPG, kerosene, or electricity. ${ }^{23}$ The association remained significant after controlling for other variables. In a case-control study of Mexican women aged $>40$ years who cooked with traditional stoves, Perez-Padilla and colleagues also found that increased exposure to wood smoke was associated with an increased risk of chronic bronchitis after adjusting for other key variables. ${ }^{24}$ Clinical studies from Mexico, ${ }^{25} \mathrm{Iran},{ }^{26}$ and New Guinea $^{27}$ of patients with lung disease have also suggested long term exposure to biomass fuel smoke as the most likely explanation for the diseased lungs since the patients in these studies were either non-smokers or rarely smoked and exposure from industrial pollution was non-existent. Studies from north India noting the high prevalence of chronic lung disease among women have also implicated indoor smoke from cooking fuels as the most likely explanation. ${ }^{28}$ Studies of acute respiratory infections in children which found a relationship with exposure to domestic biomass fuel combustion $^{29}$ also lend support to these findings because of the well documented relationship between chest illness in childhood and adult respiratory morbidity. ${ }^{30}$ It should be noted, however, that a study from Brazil showed no effect of indoor air pollution on the prevalence of chronic bronchitis after adjusting for other variables. ${ }^{31}$ However, subjects with a history of childhood respiratory illness had double the risk of chronic bronchitis compared with those without such a history after adjustments were made. A study from Ladakh, India also failed to show an association between winter pollution levels and chronic cough or chronic phlegm. However, a significant negative association was found between winter pollution levels and the ratio of forced expiratory volume in one second $\left(\mathrm{FEV}_{1}\right)$ to forced vital capacity (FVC) in women. ${ }^{16}$

While the present study suggests an association between chronic bronchitis and indoor air pollution, it has a number of important limitations. Firstly, the sample sizes were very small due to the small size of the study villages. This study, like others, also suffers from the inherent limitations of observational studies. Important among these is the potential for reporting bias, although in this study response rates were high and there was no obvious difference between responders and nonresponders. Another potential limitation of the study was the fact that the questionnaire was carried out by a single interviewer. An approach which includes several interviewers may have been more objective. In addition, the study did not include individual exposure data leading to the potential for misclassification of exposure. Logistic considerations did not allow for measuring pollution exposure for each subject, but rather total exposure for groups (men or women) only in the households in which $\mathrm{PM}_{10}$ was sampled. We would argue, however, 
that the probability of misclassification of exposure to particulates, especially combustible particulates, is extremely low given the differences between the two villages in cooking habits and mean levels of pollution. Nonetheless, refinement of exposure assessment techniques should be a priority for future studies on the health effects of indoor air pollution. Of the studies described only the study from Maputo, Mozambique also measured pollutant concentrations. ${ }^{23}$ The others used less precise calculations of exposure leading to more serious potential for exposure misclassification. The type of cooking stove used, for example, may not provide an accurate picture of exposure since improved stoves may not be well maintained and can emit as much pollution as the traditional stoves. Asking subjects about the number of hours spent near the fire may be subject to poor recall. The lack of association in the Brazil study may in fact be due to misclassification of exposure. Finally, there was potential for confounding in this study, but this was minimised by the fact that the two villages were strikingly similar to one another. The striking similarity between the villages was not fortuitous; after identifying the outdoor cooking village it took one month of searching to match this village on the key characteristics of socioeconomic status, access to health care, subsistence base, etc.

While the results of this and other studies suggest a relationship between pollution exposure and chronic lung disease in adults, further large scale studies with improved study designs and better exposure data are needed from Bolivia and other areas of the world, both to describe prevalence rates of chronic bronchitis throughout the world better and to confirm the association more positively. The next step would be to describe the nature of the association in order to provide information on the amount of reduction in pollution that would result in substantial improvements in respiratory health. This would assist in the development of culturally acceptable and feasible alternatives to the high exposure cooking stoves currently being used by most people worldwide.

The authors would like to express their appreciation to the people of Cantuyo and Taipillanga for allowing them to work in their villages. This study was supported by the National Science Foundation and by a University of Michigan Rackham dissertation grant.

1 Department of Clinical Epidemiology, National Heart and Lung Institute, London. Respiratory disease in England and Wales. Thorax 1988;43:949-54.

2 Ball P, Make B. Acute exacerbations of chronic bronchitis: an international comparison. Chest 1998;113:199-204S

3 Cookson JB, Mataka G. Prevalence of chronic bronchitis in Rhodesian Africans. Thorax 1978;33:328-34.
4 Sofowora EO. Chronic bronchitis and asthma in a Nigerian community. In: Viswanathan R, Jaggi OP, eds. Advances in chronic obstructive lung disease. Proceedings of the World Congress on Asthma, Bronchitis and Allied Conditions, 1974. Delhi: Asthma and Bronchitis Foundation of India, 1977: 36-43.

5 Tehro OE, Husman K, Vohlonen I, et al. Atopy, smoking, and chronic bronchitis. I Epidemiol Community Health 1987;41:300-95.

6 Medical Insurance Statistical Yearbook, 1994.

7 Pandey MR. Prevalence of chronic bronchitis in rural community of the hill region of Nepal. Thorax 1984;39:331-6.

8 Woolcock AJ, Blackburn CRB. Chronic lung disease in the territory of Papua and New Guinea: an epidemiological study. Australas Ann Med 1967;16:11-9.

9 Anderson HR. Chronic lung disease in the Papua New Guinea Highlands. Thorax 1979;34:647-53.

10 Smith K. Fuel combustion, air pollution exposure, and health: the situation in developing countries. Ann Rev Environ Energy 1993;18:529-66.

11 WHO. Health and environment in sustainable development. Geneva: WHO, 1997.

12 World Bank. World development report: investing in health. New York: Oxford University Press for the World Bank, 1993.

13 Albalak R, Keeler GJ, Frisancho AR, et al. Assessment of $\mathrm{PM}_{10}$ concentrations from domestic biomass fuel combustion in two rural Bolivian highland villages. Environ $\mathrm{Sc}$ Technol 1999 (in press).

14 Medical Research Council. Standardized questionnaires on respiratory symptoms. BMF 1960;2:1665.

15 Ben Miled MT, Tanabene A, Maalej M, et al. Bronchopathies chroniques chez le femme rurale en Tunisie. In: $L a$ BC en Tunisei, Rapport au 13 e Congres Medical Maghrebin BC en Tuis

16 Norboo T, Yahya M, Bruce NG, et al. Domestic pollution and respiratory illness in a Himalayan village. Int $\mathscr{f}$ Epidemiol 1991;20:749-57.

17 Malik SK. Exposure to domestic cooking fuels and chronic bronchitis. Indian f Chest Dis Allied Sci 1985;27:171-4.

18 Fletcher CM, Elmes PC, Fairbairn AS, et al. The significance of respiratory symptoms and the diagnosis of significance of respiratory symptoms and the diagnosis of
chronic bronchitis in a working population. BMf 1959;2: chronic

19 Sharp JI, Paul O, Lepper MH, et al. Prevalence of chronic bronchitis in an American male urban industrial population. Am Rev Respir Dis 1965;92:510-20.

20 Anderson DO, Ferris BG. The Chilliwack respiratory survey. Can Med Assoc f 1963;92:1007.

21 Pandey MR. Domestic smoke pollution and chronic bronchitis in a rural community of the Hill Region of Nepal. Thorax 1984;39:337-9.

22 Dennis RJ, Maldonado D, Norman S, et al. Woodsmoke exposure and risk for obstructive airways disease among women. Chest 1996;109:115-9.

23 Ellegård A. Cooking fuel smoke and respiratory symptoms among women in low-income areas in Maputo. Environ Health Perspect 1996;104:980-5.

24 Pérez-Padilla R, Regalado J, Vedal S, et al. Exposure to biomass smoke and chronic airway disease in Mexican women. A case-control study. Am 7 Respir Crit Care Med women. A case-con

25 Sandoval J, Salas J, Martinez-Guerra ML, et al. Pulmonary arterial hypertension and cor pulmonale associated with chronic domestic woodsmoke inhalation. Chest 1993;103: $12-20$

26 Amoli K. Bronchopulmonary disease in Iranian housewives chronically exposed to indoor smoke. Eur Respir F 1998;11: 659-63.

27 Woolcock AJ, Blackburn CRB, Freeman MH, et al. Studies of chronic (non-tuberculous) lung disease in New Guinea populations. The nature of the disease. Am Rev Respir Dis 1970;102:575-90.

28 Padmavati S, Arora R. Sex differences in chronic cor pulmonale in Delhi. Br f Dis Chest 1976;70:251-9.

29 Collings DA, Sithole SD, Martin KS. Indoor woodsmoke pollution causing lower respiratory disease in children. Trop Doctor 1990;20:151-5.

30 Samet JM, Tager IB, Speizer FE. The relationship between respiratory illness in childhood and chronic air-flow respiratory illness in childhood and chronic air-flow obstruction-23.

31 Menezes AMB, Victoria CG, Rigatto M. Prevalence and risk factors for chronic bronchitis in Pelatos, RS, Brazil: a population-based study. Thorax 1994;49:1217-21. 